\title{
FACTORS AFFECTING EMPLOYEE RETENTION IN PAKISTAN
}

\author{
Areebah Nadeem ${ }^{\mathrm{a}}$, Anam Malik ${ }^{\mathrm{b}} *$ \\ a areebah_nadeem@live.com, ${ }^{\mathrm{b}}$ malikanam@lhotmail.com, \\ ${ }^{a}$ COMSATS University Islamabad Campus, Pakistan
}

\begin{abstract}
Employee retention is one of the biggest challenges faced by various organizations in Pakistan. This is occasioned by globalization that has intensified competition and increased mobility of highly skilled employees. Retention of staff is a pertinent issue in public and private organizations in Pakistan, which are operating in a highly competitive environment and hence depend on their staff for success and sustainability.

Indeed retention of employees will help the organizations to accomplish their vision and mission. This research aims to examine the impact of various factors such as rewards, career development opportunities, supervisor support, training and development opportunity, job characteristics and work life conflict on employee retention. In order to conduct this study, a sample of 219 employees was obtained from leading organizations based in Rawalpindi and Islamabad.
\end{abstract}

A total 280 questionnaires were distributed from which 219 were accepted with the response rate of $78 \%$. Six hypotheses were proposed in the study. Results reveal that factors such as rewards, supervisor support, training and development opportunities, job characteristics and work life conflict, are significantly related with employee retention. The findings of this study can be useful for the organizations in developing the retention strategies and policies, so that they could retain their valuable employees.

Moreover, it's useful for the employees as it helps in identifying such factors and reasons, which forces them to quit or leave the organization. As Pakistan is a developing country and has lots of political and economical issues. Therefore retaining valuable human resource is important for the future of our country.

Keywords: Retention Factors; Rewards; Career Development Opportunity;Supervisor Support; Training \& Development Opportunity;Job Characteristics; Work-Life Conflict.

\section{Introduction}

In the present era the rapid financial and technological development has created many changes across the globe and has also implemented different and unique changes in many business organizations. Every business organization contains many sizes and shapes and it also exhibit many differences as compared to similarities. 
But one of the most important and common factors to all of this is that success of each organization depends upon the knowledge, experience and skills of the employees within them (Erasmus et al., 2013).

Retaining the employees of an organization is the most important and crucial target for the organization because sometimes the designation and high salary is not important and enough for the employee to stay in a particular organization, there are some other factors as well which helps to retain valuable employees like career development opportunities, work environment, supervisor support, work-life conflict and rewards (Monday, 2011).

The demands of workers have been increased rapidly from every aspect, not only perks and salaries but also the work experience and in cultural context also, in which it usually occurs. In order to develop a strong and effective retention plan for the present employment market, it is very important to realize the expectation and varying needs. If all the retention strategies and plans are not properly implemented in the business processes, then all efforts being made since recruitment would be proved wasted (Coetzee \& Schreuder, 2012).

\section{Statement of the Problem}

For every organization whether its public or private employee retention has a great importance. If a public or a private company fails to retain its valuable employees, it leads to increases cost of turnover, which is one of the main factors that affect the company's success. Additionally, it's difficult to find suitable replacement for valuable human resource. Therefore it's the need of this current era to find factors that can help us in improving employee retention. So, the main concern of the study is to find such factors (like rewards, career development opportunity, supervisor support, training and development opportunity, job characteristics, work-life conflict) that have direct impact on employee retention in public and private organizations of Pakistan. If the issue of employee retention is resolved in these sectors timely by appropriate plans and policies, it can save the future of our homeland.

\section{Objectives of the Study}

The purpose of this study is to identify and analyze the factors that affect employee retention. This would helps to contribute towards the most important, and a big challenge of an organization that is employee retention, which is a very important and crucial part of human resource management. So, the main objective of this study is to explore the major factors of employee retention in public and private organizations of Pakistan and to analyze the relationship of such factors that affect employee retention.

\section{Significance of the study}

The current study has a great importance in context of developing countries like Pakistan. Nowadays Pakistan is going through a lot of political and economical problems which has given birth to high inflation rate in the country. Therefore, it's important to retain their valuable employees for our country's future. The purpose of this study is to analyze and discuss the new emerging factors that can influence employee retention the most and to analyze its impact on employee retention so that the turnover intention among Pakistani employees would be controlled. Similarly, it can be said that employee retention in the current business environment is of greater importance because in today's modern working world, which consists of competitive market, rapidly changing technology; it helps to keep the employees committed and engaged with the organization. 
This research can be useful for the employees in identifying such factors and reasons, which forces them to quit or leave the organization. Additionally, this study can be helpful for the top management to realize that what strategies should be made to retain their valuable employees and would allow them to think how to implement different strategies in order to retain their employees and for the organizations success also. Moreover, some other facts that this study may help in achieving organization success is that when employee retention will be enhanced this will overcome the problems caused by high turnover like help in reduction of cost of employee turnover, help in avoiding the loss of company's knowledge, in maintaining the goodwill of the company and also reducing the interruptions in the customer service.

\section{Literature Review}

Employee retention is always a matter of great importance for the employer and policy makers of an organization as they are the ones on which success of the organization depends. As nowadays in Pakistan the economic and political situation is not that good that's why many of the good employees are willing to leave their jobs for better opportunity. Whether it's a public organization or private both are facing serious loss of their valuable human resource. If the employees are not treated well they would leave the organization and if this process continues the company may face big problem in its future (Dow, 2012, Krell, 2011).

According to a research there are certain inside factors that trigger the turnover intention among employees more than the outside factors. Therefore, it's the duty of an organization to pay more attention to the matter of employee retention so it would be improved (Rabia et al., 2011). The phenomena of employee retention has a great importance as according to Akila (2013) retaining employees is very important as the cost of turnover can effect companies budget. Secondly, the employee who will leave the organization will take the valuable information about the company with him. Thirdly, employees are a bridge between customer and the organization. They share a relationship of trust and when an employee leaves an organization the customer don't accept his or her replacement so easily, which cause interruption in customer services.

\subsection{Retention In Relation With Public and Private Sector Of Pakistan}

Retaining employees is always a great issue for developing countries like Pakistan. Cause of the unstable political and its economic condition people are fed-up with their jobs as the salary they get for it is not enough to fulfill their needs. As a result they become frustrated and couldn't perform their hundred percent as they are mentally stressed. Therefore, it is one of the main issues why a person leaves his job. This problem is almost faced by every organization in Pakistan whether it's public or private. In private and public companies of Pakistan employee retention depends on the factor that how much the employee is satisfied by his or her job. Certain factors like lack of supervisor support, lack of career development opportunities, lack of training and development opportunity, dissatisfaction with job and high work-family conflict causes employee dissatisfaction. Moreover, public employees appreciate and request good leaders/managers as the staff generally highly appreciate good management practices such as better communication between staff and management; employee involvement in decision-making in the workplace; teamwork; and challenging assignments. Such factors are conducive to improved organizational performance (Uma, 2010).

In terms of rewards, in public companies staff has not embraced a performance culture. Although the need to perform is accepted in principle, the use of individual rewards and sanctions (central to performance management) is regarded with skepticism by many since they are perceived not to be administered in a fair manner in comparison with private companies (Dockel, 2006). In terms of job characteristics, most of the public sector organizations do not provide job description (JD) to their workers nor do they analyze their JD's on monthly or quarterly basis, which result in shallow performance of their workers and adversely impact organization performance (Krell, 2011). 
In terms of work-life conflict policies, public sector is much helpful in family related issues whereas in private sector it requires job accomplishment timely irrespective of any personal or family requirement or commitment of an employee. This is one of a reason why private sector employees leave the organization. On the other hand, staff prefers public service employment on private sector. Some of the motives for work in the public sector are conducive to performance such as career prospects as public sector organizations are bureaucratic in nature, hierarchical and staffed mainly by permanent career officials. These employees are employed until retirement and are promoted based largely on seniority and remunerated at standard rates within the unified salary structure. Other motives are detrimental to performance such as staff appreciation of the comparatively slack work discipline in the public sector, which is one of the motives for working there and not in the private sector (Erasmus et al., 2013).

\subsection{Factors Influencing Employee Retention}

Employees are considered as the very important part of every corporation as they are the one who produce or deliver product or services (Bashir et al., 2009). They are considered as the supreme essential resource in comparison to other resources such as machines, material etc (Erasmus et al., 2013). Dockel (2006) suggested the factors that can affect employee retention are compensation, job characteristics, supervisor support, training and development opportunity, career opportunities and work-life policies. The factors that are chosen and are more relevant to this research are as follows:

- Rewards

- $\quad$ Career Development Opportunity

- Supervisor Support

- Training and Development Opportunity

- Job Characteristics

- Work-life Conflict

These factors are chosen in this research because they have strong literature background and have direct impact on employee retention.

\subsubsection{Rewards}

In different studies reward is basically defined as something that is given by the organization to its employees in response of their valuable contribution and great performance and it's something that is desired by the employees and it's to motivate them (Agarwal, 1998, Silbert, 2005). In addition to that Silbert (2005) stated that it's important that the reward should have a long-lasting impression on the worker, as this will make him feel that he is special and his efforts are valued. Reward is one of the important factors to control the element of turnover in employees and enhances employee retention (Coetzee \& Schreuder, 2012).

\subsubsection{Extrinsic and Intrinsic Rewards}

Reward can be extrinsic or it can be intrinsic. Extrinsic rewards mean it can be paid in the form of cash also known as financial rewards, formal reward, monetary rewards and pay for performance it can be paid as bounces. Whereas on the other hand, employee of the month can be categorize as an intrinsic reward also known as non-financial reward, informal reward and non-monetary rewards. It is said that both types of rewards affect the employee motivation level whether they are extrinsic or intrinsic reward in nature (Yap et al., 2009). According to a research, whenever an employee achieved his or her goal. He is facilitate with something as an appreciation and that something can be in form of formal or informal reward depends and varies from case to case. These rewards make the employee realize that his effort, skills and time are valued. This not only motivates him but also encourage others to work hard (Coetzee \& Schreuder, 2012). Hence following hypothesis could be proposed. 


\subsubsection{Career Development Opportunities}

Career development Opportunity is one of the strongest pillars of employee retention. It can be defined as a well-organized and planned effort, which is done by the organization itself to retain its talented employees. The main objective of this effort is to maintain a balance between organization's workforce requirements and individual career needs. The new and big challenge for the HR professionals is to recognize the different developmental strategies, which can encourage the employee's commitment to the firm's mission and goals. So the employees may become motivated and it will also help the firm to maintain a competitive advantage over others (Dockel, 2006). In a country like Pakistan, where the political and economical sectors is quit unstable, the global economic changes are giving birth to the career related problems that cause employee turnover. These dissatisfactions force an employee to look better opportunity and are a cause of high turnover (Monday, 2011).

\subsubsection{Internal and External Career opportunities}

Dockel (2006) suggested that career-developing opportunities could be internal career developing opportunity and external career developing opportunity. Internal career developing opportunity includes internal job switching, so one can learn maximum. Moreover, recruiting internally helps the organization to save recruitment cost. These career orientations policies strengthen employee and organization relationship (Mitchell et al.,2001).It is suggested in various studies that the three main necessities of the employee is career development, knowledge, and growth. It's seems like if the employee feels he is learning and developing he is less likely to leave the job. But on contrary, external and alternative job opportunity is also a major cause of employee turnover. The employee also recognizes the skill development opportunities, which is the capability of employee to attain and manage his or her job challenges and career advancement as one of the main attraction to organization as these opportunities will give them a chance to polish their capabilities and skills. This also gives a sense of satisfaction to the employees (Kreisman, 2002).

\subsubsection{Supervisor Support}

Supervisor and employee relationship plays a great role in employee retention. As supervisors are the people who represent high management of an organization so it's their duty to manage employees in a better way. Supervisor support is one of the major issues that can cause dissatisfaction among the employees with their jobs if they are not treated well. The opinion of workers that the firm supports them has a direct and positive relation with their commitment with the firm. Supervisor support has significant relationship with turnover intention (Kemboi et al., 2013).

\subsubsection{Supervisor's behavior, recognition and feedback}

Supervisor plays a very important role in an organization's success. It's his responsibility to interact with the employees individually, identify their capabilities and to motivate the valuable employees at the right time. As retention is a game of satisfaction as long as the employee is satisfied with his or her job, he or she will be staying with the organization. Therefore sincere managers will support the talented employees to obtain job satisfaction (Kreisman, 2002). Effort recognition and feedback are one of the basic necessities of employees that encourage them to work hard and make them feel their effort is valued by the organization, this strengthen the organization and employee bond and prolongs their stay with the organization, that enhances employee retention. Additionally, supportive supervisors also play a great role in enhancing the capabilities of his employees and coworkers and help them to learn from their mistakes and to face new challenges. Furthermore, if at various levels of an employee's job certain opportunities are provided, this can 
help in increase in employee's capabilities and skills, and will keep them motivated (Coetzee \& Schreuder, 2012).

\subsubsection{Training and Development Opportunity}

Training and development opportunity is considered as another important factor that have a great influence on employee retention, as it help in lowering the turnover intention among employees (Dockel, 2006, Wetland 2003). Training and development opportunities have a positive direct relationship with employee retention. Training can be defined as a planned intervention that is design to increase the determinants of individual employee job performance (Waleed et al., 2013). Organization can develop and provide such activities for his employee, which gives them the opportunities to enhance their skills and help in their professional growth and development (Kreisman, 2002). Every organization spends a lot of money for the employee developing programs. Wetland (2003) states that an investment on human capital is made by both groups' employees as well as organization in the form of training, that helps in development and improvement of the employees skills. This skill developing and improving program should be started just after an employ hiring. But on the other hand some researches states that some organization by intention delay the training and development program to see whether the employees personal value is compatible with the organization culture or not.

Nowadays every company wants to remain competitive and to remain competitive there is a need to develop skills and for that employee training is very important. Training helps in strengthening the relationship between an employee and the organization. As the employees get good training opportunities they get more satisfaction and this prolongs their stay within the organization and makes them feel they are valued to the organization (Anis et al., 2010).

\subsubsection{Job Characteristics}

Job characteristic is another important variable that has a great impact on employee retention. It includes skill variety and job autonomy Dockel (2006). The employees that have expertise and skills about core services and products are known as knowledge workers. These employees prefer jobs in which they can establish, utilize and polish their skills by challenging assignments (Uma, 2012).

\subsubsection{Job Autonomy and Skill Variety}

Job autonomy is just like employee empowerment it's the ability of an employee to use his or her power in performing his or her task. Also known as the level to which an employee exercises his or her power in relation to their job. In other words it's the degree to which an employee is given independence, freedom and discretion for performing his job and determining procedures in executing his or her job or task (Dockel, 2006). Moreover, it's the ability of professionals to decide work patterns. Job autonomy makes the employee feel that he is free to do his or her task without any interference or disturbance by the external or internal source. In other words, it gives the power to the employee to make his or her own decision in performing it's task. This gives the opportunity to the employee to develop and use his or her different ideas in implementing their tasks and make it easy. It is said that the more liberty given to the employee in performing his or her duty the less clashes he face within the organization with his or her colleagues, and the less clashes he face the more his intention to stay in the organization increase (Sharf, 2010). Whereas skill variety signifies the degree to which a specific job demands an employee to use various skills, abilities and knowledge. Moreover, if an employee is given the opportunity to use various skills in his or her job it decreases boredom and increases job satisfaction keep employees motivated which lead in the reduction of employee turnover intention (Ali, 2010). 
5.2.6 Work-life Conflict

Work-life conflict is one of the major pillars of employee retention. It can be defined as clash between work and family life. As the demand of both, conflict each other in meeting their demands. The emerging technology, long working hours work pressures and high demanding jobs made it very difficult to keep a balance between family and work life and then the situation of conflict arises. So it plays a very important role in retaining the employees of a particular organization. There are various factors that can help in the reduction of work-life conflict such as stress. Moreover, the efficiency and functioning of a firm has a direct significant relationship with employee satisfaction (Sikander et al., 2012). Work life conflict has inverse relationship with productivity and performance of the organization. In Pakistan the employees of the different private and public organizations face stress in their job more than employees of western world. To achieve goals and objective of an organization it's important for it to keep its employees satisfied, happy and stress free as more as possible. As these work life conflict has a negative relation with organization performance it can be said that work life conflict such as stress is a big hurdle in organization success (Afzal et al., 2011).

\section{Research Methodology}

The main purpose of this research is to identify and analyze the factors that affect employee retention in Pakistan. The primary data collection method used in this research is collected via questionnaires. The time horizon of this study is cross-sectional. Convenience testing is a testing strategy that acquires and gathers the appropriate information from the example or the unit of the research that are easily available.

The population on which this research analysis is undertaken is the employees of public and private companies of Pakistan. These two sectors are also considered as revenue generating sectors. In a country like Pakistan where the political and economical condition is not stable losing valuable resource can be a big hurdle for the future of our country. For the research analysis two public and two private sector leading organizations were chosen that are situated in twin cities (Rawalpindi and Islamabad). The organizations that are chosen from public sector are State-life Insurance Company and National Institute of Electronics. Whereas the private sector organizations that are selected for this research is Seronic and Saif Solutions Limited. For this study, there were six independent variables used in this research, initially 280 questionnaires were distributed that is 70 questionnaires per organization. The number of questionnaires returned by the respondents after filling were 230 out of which 21 questionnaires were discarded. Therefore a sample of 219 questionnaires was obtained.

\section{Hypothesis}

According to this study which investigates the factors impacting employee retention in Pakistan, following hypothesis were proposed:

H1: There is a significant positive relationship between rewards and employee retention in Pakistan.

H2: There is a significant positive relationship between career development opportunity and employee retention in Pakistan.

H3: There is a significant positive relationship between supervisor support and employee retention in Pakistan. 
H4: There is a significant positive relationship between training and development opportunity and employee retention in Pakistan.

H5: There is a significant positive relationship between job characteristics and employee retention in Pakistan.

H6: There is a significant negative relationship between work-life conflict and employee retention in Pakistan.

\section{Result and Discussion}

The demographic characteristics of the respondents show that $85.4 \%$ of respondents were male and $14.6 \%$ were female in which $17.8 \%$ are single and $81.7 \%$ are married. Moreover, in terms of designation $25.1 \%$ respondents belongs top management, $54.3 \%$ belongs to middle management and $20.5 \%$ of respondents belongs to low level management which shows majority of respondents belong to top and middle level management. Similarly, in terms of respondent age out of 100\%, 14.6\% of employees are 20-29 years old. Whereas, $44.3 \%$ respondent belongs to age group 30-39years, 31.5\% of respondents belong to $40-49$ years and $9.6 \%$ of respondents belong to the age group 50 years or over which shows that majority of the respondents belong to the age group 30-39 years and 40-49 years. Furthermore, in terms of employee level of experience $5.9 \%$ of total respondents experience is less than one year, $4.6 \%$ of respondents have job experience of $1-2$ year $26.9 \%$ of employees have the job experience of 3-5 years and $62.6 \%$ of respondents have the job experience of 6 years or over.

Table1. Descriptive Statistics of Variable

\begin{tabular}{lll}
\hline Variables & Mean & $\begin{array}{l}\text { Standard } \\
\text { Deviation }\end{array}$ \\
\hline Rewards & 3.1605 & 0.70 \\
Career Development Opportunity & 5.0365 & 0.89 \\
Supervisor Support & 2.9826 & 0.46 \\
Training and Development Opportunity & 3.0753 & 0.91 \\
Job Characteristics & 3.2351 & 0.43 \\
Work-life Conflict & 3.1865 & 0.46 \\
Retention & 3.1963 & 0.76 \\
\end{tabular}

\subsection{Reliability and Validity}

The method that is used to check the reliability of the data in this research is Cronbach's Alpha's method. According to different statistical theories the acceptable range of cronbach's alpha's $(\alpha)$ is more than or equal to .70 . The total scale cronbach's alpha's value is 0.810 . Therefore, cronbach's Alpha's value lies in acceptable range. Content validity assures that the data set has sufficient and adequate quantity of items that would work alongside the concept (Sekaran, 2009). Rewards, Career Development Opportunities, Supervisor Support, Training and Development Opportunity, Job Characteristics and Work-Life Conflict (independent 
variable) and Employee retention (dependent variable) sig value is 0.000 , therefore, these variables satisfy the validity test.

\subsection{Correlation Analysis}

The value of independent variable rewards and employee retention is $r=.277$ ( $p<0.01)$. This coefficient shows that there is a positive relationship between the rewards and employee retention. Career development opportunity also shows a positive correlation with employee retention with the value of $r=0.304(p<0.01)$. Supervisor support shows a positive correlation with dependent variable employee retention with the value of $\mathrm{r}=0.241(\mathrm{p}<0.01)$ which means the employee retention could be increased by the increase of supervisor support. Likewise, positive and significant relationship is seen between training and development opportunity and retention that is $\mathrm{r}=0.355$ ( $\mathrm{p}<0.01$ ). Similarly, correlation between job characteristics and employee retention is $\mathrm{r}=0.214(\mathrm{p}<0.01)$. This means there is a positive correlation between job characteristics and employee retention and they also contain a significant relationship. Whereas, work life conflict shows a negative correlation and significant relationship with employee retention with the value of $r=-0.25(\mathrm{p}<0.05)$.

Table2. Correlation between Independent Variables and Employee Retention

\begin{tabular}{lll}
\hline Variables & $\begin{array}{l}\text { Pearson } \\
\text { Correlation with } \\
\text { Retention (r) }\end{array}$ & P-value \\
& .277 & .000 \\
\hline Rewards & .304 & .000 \\
Career Development Opportunity & .241 & .000 \\
Supervisor Support & .355 & .000 \\
Training and Development Opportunity & .214 & .001 \\
Job Characteristics & -.025 & .047 \\
Work-life Conflict & & \\
\hline
\end{tabular}

\subsection{Regression Analysis And Hypothesis Testing}

In this study there are six independent variables and one dependent variable. The dependent variable is employee retention and the six independent variables are rewards, career development opportunity, supervisor support, training and development opportunity, job characteristics and work life conflict. The regression equation is as follows:

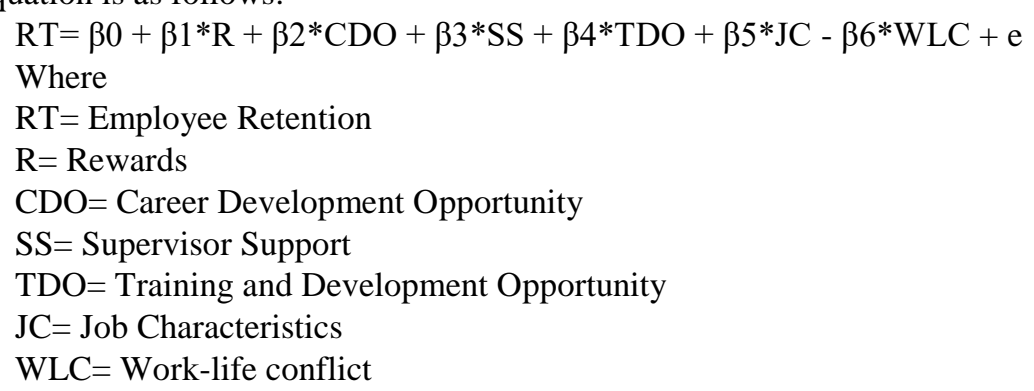


Table3. Results -Dependent Variable: Retention

\begin{tabular}{lll}
\hline Variables & Co-efficient & P-value \\
\hline Constant & 3.084 & .039 \\
Rewards & .076 & .048 \\
Career Development Opportunity & .054 & .274 \\
Supervisor Support & .122 & .052 \\
Training and Development Opportunity & .124 & .000 \\
Job Characteristics & .175 & .044 \\
Work-life Conflict & -.126 & .017 \\
F & 10.603 & .000 \\
R-square & 0.232 & \\
& & \\
\hline
\end{tabular}

Results shows that $23.2 \%$ of the variance in dependent variable that is employee retention is explained by the independent variables that are supervisor support, job characteristics, career development opportunity, work life conflict, reward and training and development opportunity as the value of R square=0.232. It also shows that the model is significant with the value of $F=10.603$. The above table also shows the impact of various independent variables on employee retention. The results revealed that rewards with the value of $(\beta 5=$ $0.076, \mathrm{p}<0.05)$ indicates a positive and significant relationship with dependent variable employee retention that leads to the acceptance of hypothesis H1, Whereas, the value of career development opportunity $(\beta 3=0.052, p>0.05)$ shows that it has a weak positive and insignificant relationship with employee retention that rejects the hypothesis H2. Supervisor support has a value of $(\beta 1=0.122, p \leqslant 0.05)$ which shows that there is a positive and significant relationship between supervisor support and employee retention; hence the hypothesis (H3) is accepted. Training and development opportunity with the value of $(\beta 6=0.124, p<0.01)$ illustrates a positive and significant relationship with employee retention. Therefore, the hypothesis $\mathrm{H} 4$ is accepted. Similarly, job characteristics with the value of $(\beta 2=0.175, p<0.05)$ also indicate a significant positive relationship with employee retention that results in accepting the hypothesis H5. However, work life conflict with the value of $(\beta 4=-0.126, \mathrm{p}<0.05)$ indicates a significant negative relationship with employee retention, therefore the hypothesis $\mathrm{H} 6$ is accepted.

\section{Limitations and Future Research}

There are different factors that affect employee retention but due to time and resource constraint others are not taken for research. Additionally, the sample that is used in this research is restricted to twin cities of Pakistan (Rawalpindi and Islamabad), however other cities within the Pakistan can also be taken for future research with large sample size. Moreover, according to the rules of some organizations, they don't allow their employees to indulge in such kind of activities. Only one method of collecting data is used in this research that is via questionnaires, whereas other data collection techniques can also be used for the collection of data such as interviews. Financial problems in terms of photocopying, transport costs were faced. However the researcher solicited funds from family friends and also savings from work. The researcher also faced problems of unresponsive respondents in conducting the research. This was dealt with by giving them sample 
time to fill the questionnaires during their free time. Further research should be carried out to find out the extent to which other factors such as flexible job timings or recreational activities affect the employee retention.

\section{Implications}

In the light of this research the importance of this study can be viewed from two dimensions: theoretical contributions and practical implications. Theoretically, the study fills an important gap in the literature; that is, exploring retention factors in public and private sector of Pakistan. Therefore, the findings of this study can add to the existing body of the literature and can serve as a starting point on which future studies can be built in context with private and public companies of Pakistan. On the practical side, this study can help the topmanagement decision makers of surveyed companies to enhance the major factors that may better develop their employees'retention and thus meeting organizational goals and objectives. Therefore, the top management of the surveyed companies are recommended to review policies to establish such fair reward distribution system that will take in account the performance of the employees monthly, quarterly or annually by awarding them gift vouchers for their effort in achieving the targets and managing stress and strain of their job or by awarding them champion of the month or year on achieving milestones of the project.

Moreover, there commitment with organization can also be enhanced by providing them bonuses for their hard work and performance. As money is not the only thing that an employee desires they need respect, recognition and motivation to work hard. The most common reasons that forces an employee to leaves their job in a public and private sector is the delay in promotions by improper promotion criteria, conflicts with supervisor and lack of opportunities for learning and growth.

Therefore, to retain employees in this sector it is recommended that supervisors are needed to cooperate with employees in terms of their behavior, feedback and effort recognition. With reference to the study it is observed that the employees of public and private sector are dissatisfied by the lack of opportunities for learning and growth hence a counseling system could be established regarding counseling employees for their career and training development programs, which will enhance employee loyalty with the organization. Additionally, the top management of the surveyed companies should realize the importance of such factors that has adverse affect on employee retention (conflicts and dissatisfaction with retention factors). As work life conflicts can seriously negatively impact the stay of employees within the organization. For this the top management should introduce such policies (such as flexible schedules, childcare facilities and telecommunicating programs) to cater this employee retention problem. Finally, it is envisaged that this study will lead to increased awareness of retention process among top management and the need for further research in the subject area.

\section{Conclusion}

The aim of this research was to investigate and analyze such retention factors that encourage employees to stay in the organization. The literature shows that retention factors are critical and should be well addressed by any organization in order to meet its goals and objectives. In this research study it was hypothesized that the various retention factors such as supervisor support, job characteristics, career development opportunities, rewards, and work-life conflict and training and development opportunities have direct impact on employee's intention to stay. The regression result shows that in the current scenario training and development opportunities have the most significant effect on employee retention. Which means if employees are given 
better opportunities of training and development there are more chances that the employee will stay longer with the organization?

After training and development opportunity the most significant factor that influence employee retention is work-life conflict. It can be analyzed that as most of the respondents that respond to the questionnaire were married that's why they preferred work-life conflict to other factors. It can also be said that in Pakistan most of the people want to settle in abroad or want to switch their job within the country because other companies gives better work life benefits. Therefore, it is one of the great reasons why an employee leaves an organization. In the light of this research study, after training and development opportunity and work life conflict the most significant factor that impact employee retention is job characteristics. This means if a person is given proper authority to do his or her task on their own there is a chance of increase in employee retention. The only factors whose affect was positive but insignificant in this research was the career and development opportunity. The reason behind it that it could be the selected organizations where the research was conducted people do not bother for career opportunity as much as the other factors. There can be few reasons behind it as the public and private sector of Pakistan is quite saturated and there are quite a few number of career development opportunities in any department. As a matter of fact favoritism is common whenever there is lesser number of opportunities than number of candidates for it. Whenever there is an opportunity the personal liking and disliking of the top management adversely affect the selection criteria. Moreover the good workers do not have time to run after their bosses and most of them do not have the awareness of their rights and organization rules regarding career development opportunity. This gives the chance to the less competent employees they took the advantage of the scenario and play with rules to avail the opportunity.

Therefore, to cope with this type of mismanagement the organization needs to develop counseling system. Moreover, in agreement with the observation and results of the current study, rewards and supervisor support are also considered as significant factors that influence employee retention but less significant than others. Finally, it can be summarized as if the employees are provided with proper training and development opportunities, better facilities to minimize work life conflict, proper supervisor support, rewards and job characteristics then it will not only motivate them to work better, it would also ultimately decrease their intention to leave the organization to a greater extent.

\section{References}

Agarwal., 1998. Reward Systems: Emerging Trends and Issues. Canadian Psychology 39(1), p. 60-70.

Akila, H., 2013. "Factors Determining Employee Retention”, International Journal of Management \& Information Technology, 6(3).

Ali, H., \& Aroosiya, M., 2010. Impact Of Job Design On Employees’ Performance, University of Kelaniya, Sri Lanka.

Anis, A., Rehman, I., Nasir,A., \& Safwan,N., 2010. Employee retention relationship to training and development, African journal Business management , 33(1),p. 60-70.

Bashir, S., Tirmizi, S. R., Noor, A., \& Shoaib, M., 2009. Determinants of Employee Retention in Telecom Sector of Pakistan, Proceedings 2nd CBRC, Lahore, Pakistan.

Coetzee, F., \& Schreuder, D., 2012. Personnel Psychology: An applied perspective. Cape Town: Oxford University Press

Dow, S., Tom, M., \& Mark, R., 2012. Retention of Key Talent and the Role of Rewards, World at Work Journal, 20 (12).

Dockel, A., Basson, J.S., \& Coetzee, M., 2006. The effect of retention factors on organizational commitment: An investigation of high technology employees, SA Journal of Human Resource Management, 4 (2), p. 20-28. 
Erasmus, B.J., Loedolff, P.V.Z., Mda, T.V., \& Nel, P.S., 2013. Managing Training and Development. Oxford University Press: Southern Africa.

Krell, E., 2011. “The global talents mismatch.” HR Magazine, 65(6).

Kreisman, B.J., 2002. Insights into employee motivation, commitment and retention. PhD Research/White paper, University of Texas.

Kemboi, A., Biwott, G., Chenuos, N., \& Augustine, N., 2013. Skill variety, feedback and employee performance: A case of teaching and referral hospital, European Journal of Business and Management, 5(19).

Mitchell, J., Terence, R.B.C., \& Haltom, T. W., 2009. How to Keep Your Best Employees: Developing an Effective Retention Policy. Academy of Management Executive, 15(4), p. 96-99.

Monday, O.,2011. Problems and Prospects of Private Sector Organizations in Nigeria, International Journal of Business and Management, $6(4)$.

Rabia, A., Sadaf, S., Mahwish, A., \& Shama, S., 2011. Work-Family Conflicts: Relationship between Work-Life Conflict and Employee Retention - A Comparative Study of Public and Private Sector Employees, Interdisciplinary Journal of Research in Business, 1(2), p. 18-29.

Sekaran, U., 2009. Research Method for Business: A Skill Building Approach. 4th Edition, Wiley India, New Delhi.

Sharf, R.S., 2010 .Applying career development theory to counseling (5th ed.) Belmont, CA: Brooks/Cole, Cengage learning.

Silbert, L.T., 2005. The effect of Tangible Rewards on Perceived Organizational Support, International Journal of Management Sciences.

Sikander, A., Mujtaba, B. G. \& Afza, A., 2012. Stress, Task, and Relationship: Analysis across Two Culturally Diverse Countries. International Business and Management, 4(2), p. 33-40.

Uma, S., 2010. Public Sector Pensions and the Challenge of an Ageing Public Service, International Journal of Business and Social Science, 4(9).

Waleed, H., Amir, R., Rida, Q., Rida, J., \& Sidra, S., 2013. The Effect of Training on Employee Retention, Global Journal of Management and Business Research Administration and Management, 13(6).

Wetland, D., 2003. The strategic training of employee's model: balancing organizational constraints and training content. In S.A.M. Advanced Management Journal, p.103-107. 